Rev. Latinoam. Psicopat. Fund., São Paulo, 20(1),197-200, mar. 2017

http://dx.doi.org/10.1590/1415-4714.2017v20n1p197.14

El caso Morillo: crimen, locura y subjetividad

en la España de la Restauración

Ricardo Campos

Madrid: Consejo Superior de Investigaciones Científicas/Frenia,

2012, 270 págs.

\title{
O caso Morillo: versões e controvérsias de um crime
}

Francis Moraes de Almeida*1

Na noite de 28 de outubro de 1883, na rua San Vicente da cidade de Madrid, o jovem médico Manuel Morillo disparou contra os pais de sua noiva, matando a mãe e ferindo o pai. Tal crime dá título à obra de Ricardo Campos e poderia levar o leitor a considerar que ela se inscreve na conhecida tradição de monografias sobre crimes célebres; no entanto, o que se encontra aqui é bem mais do que isso. Campos emprega o que chama de sincretismo metodológico para descrever como a identidade de Morillo é desdobrada em pelo menos três instâncias após o seu crime. Em princípio, a imprensa caracteriza o crime como inexplicável e destaca suas características mais violentas na tentativa de tornar seus atos compreensíveis ao público. A justiça inicia uma investigação,

\footnotetext{
${ }^{* 1}$ Universidade Federal de Santa Maria (Santa Maria, RS, Br).
} 


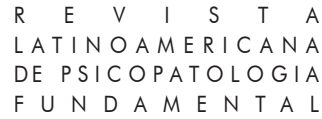

logo as cartas do jovem médico à noiva e a seus familiares e seu caderno de anotações são empregados para delinear a premeditação de seus atos. Por fim, os psiquiatras intervêm a pedido da justiça e compreendem todas as condutas e escritos de Morillo como manifestações de uma patologia à qual suas condições hereditárias o predispunham, diagnosticando-o como portador de loucura epilética. Ao longo dos quatro capítulos, o livro apresenta a construção dessas diferentes identidades de Manuel Morillo.

O primeiro capítulo aborda o modo sensacionalista como o crime foi noticiado pelos principais jornais de Madrid, através de descrições ricas em adjetivos que apresentam a cena do crime tal qual uma peça teatral. Ao fim do julgamento, foram lançados dois livros, El crimen de la calle San Vicente, do advogado e jornalista policial Vicente de Camara Quadros e El processo Morillo, creditado ao jornalista Augustín Saes Domingo. Ambos merecem destaque por terem vendido milhares de exemplares, o que reflete a importância do caso para a opinião pública, e constituíram fontes essenciais para a própria elaboração da obra de Campos, já que compilam as cartas de Morillo, seus escritos que antecedem o crime e impressões sobre o confronto entre juristas e psiquiatras no tribunal.

O segundo capítulo dedica-se a apresentar a subjetividade de Morillo a partir de seus escritos. Campos mostra como o autor do crime se autorrepresenta e justifica seus atos, e como seus escritos são lidos e ressignificados pelas três instâncias: os psiquiatras para justificar cientificamente sua disciplina; os juristas destacando sua maldade e seu desprezo pela moral e pelas leis; e os jornalistas para aumentar as vendas dos jornais. O autor nos conta que Morillo conhece sua noiva Amparo Fernández em uma das reuniões dominicais na casa da família. Adiante, o pai da noiva descobre que sua filha havia perdido a virgindade com o noivo, e este pede permissão para levar Amparo para morar consigo sem que estivessem casados. O noivado é cancelado, diante do que Morillo passa a escrever cartas a Amparo, propondo que fugisse com ele, e posteriormente a seu pai, ameaçando-o para que cedesse à sua proposta de concubinagem. Escreve em tom cada vez mais ameaçador, até que é aberto um processo. Após longa negociação, a acusação é retirada mediante um acordo. Morillo passa a escrever o seu caderno, que intitula Mi declaración.

Diante do potencial fascínio que os escritos de punho do próprio criminoso poderiam exercer sobre o analista, Campos toma uma atitude crítica. Destaca que os escritos de Morillo não são subversivos como os seus contemporâneos alegam, mas extremos na misoginia e machismo que são 


\section{RESENHAS BIBLIOGRÁFICAS}

característicos do período. As extensas e insistentes justificativas de Morillo para o cumprimento de seus desejos são um prato cheio para a imprensa da época, pois ele emprega um tom melodramático próximo dos romances de folhetim, bem como permitem aos psiquiatras identificar claras mostras de sua loucura, enquanto os juristas não veem mais do que premeditação encoberta por simulação de loucura.

O terceiro capítulo apresenta o julgamento e o papel dos peritos psiquiatras, evocados em virtude das dúvidas suscitadas quanto à sanidade mental de Morillo. No julgamento, os dois psiquiatras que o periciaram a pedido da defesa atestam seu diagnóstico de loucura epilética. Um dos três médicos forenses chamados pelo promotor concorda com o diagnóstico de loucura epilética, outro apenas indica que, mesmo que fosse louco antes do cometimento do crime, Morillo estava são no momento do ato e, por fim, o terceiro médico nega de modo veemente a loucura do acusado e ataca frontalmente os métodos e a pretensa cientificidade dos colegas. A posição do juiz, do acusador privado e do promotor representa a resistência dos juristas à teoria da degeneração e à Antropologia Criminal. Os juristas criticam a alegação da existência de estigmas físicos no réu, a ausência de mensurações para atestar a cientificidade das conclusões, e indicam a falta de fundamentação para o diagnóstico, dado que não se baseavam em observações feitas pelos peritos, mas em relatos de carcereiros e, sobretudo, nos escritos do próprio Morillo. O resultado do julgamento é a negação da alegada insanidade do acusado e sua sentença de prisão perpétua.

O quarto capítulo retrata os últimos anos da vida de Morillo, longe da atenção dos jornalistas, mas ainda alimentando vivas controvérsias entre psiquiatras e juristas. Nos meses seguintes a seu encarceramento, ele continua apresentando comportamentos estranhos, desenha uma cruz sobre sua cama e as letras J. D. (Justiça Divina) sobre ela, além de apresentar acessos de fúria e ataques epiléticos. Ao longo dos três anos seguintes, quatro expedientes de sanidade mental atestam sua insanidade crescente. Em 1887, finalmente Morillo é internado em um manicômio, até sua morte em 1892.

Ricardo Campos oferece uma contribuição singular ao campo das pesquisas sobre história da psiquiatria. Embora tematicamente seu trabalho esteja muito mais próximo a Eu, Pierre Rivière, que degolei minha mãe, minha irmã e meu irmão organizado por Michel Foucault, sua metodologia $\mathrm{e}$ abordagem lembra mais a micro-história de Carlo Ginzburg em $O$ queijo e os vermes. Sua abordagem extremamente detalhada do contexto histórico no qual se passa o caso Morillo e o cotejamento dos diversos matizes sob os quais 


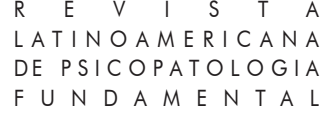

seus atos e sua vida foram interpretados e ressignificados representam uma versão crítica e compreensiva do ocorrido, sem se impor ao leitor como a mais completa ou verdadeira.

Citação/Citation: Almeida, F. M. (2017, março). O caso Morillo: versões e controvérsias de um crime. Resenha do livro El caso Morillo: crimen, locura y subjetividad en la España de la Restauración. Revista Latinoamericana de Psicopatologia Fundamental, 20(1), 197-200.

Editores do artigo/Editors: Profa. Dra. Sonia Leite

Recebido/Received: 25.11.2016 / 11.25.2016 Aceito/Accepted: 8.1.2017 / 1.8.2017

Copyright: (C) 2009 Associação Universitária de Pesquisa em Psicopatologia Fundamental/ University Association for Research in Fundamental Psychopathology. Este é um artigo de livre acesso, que permite uso irrestrito, distribuição e reprodução em qualquer meio, desde que o autor e a fonte sejam citados / This is an open-access article, which permits unrestricted use, distribution, and reproduction in any medium, provided the original authors and sources are credited.

\section{Francis Moras de Almeida}

Bacharel em Ciências Sociais e Psicólogo pela Universidade Federal de Santa Maria - UFSM (Santa Maria, RS, Br); Mestre e Doutor em Sociologia pela Universidade Federal do Ri Grande do Sul - UFRGS (Porto Alegre, RS, Br); Professor do Departamento de Ciências Sociais da UFSM; Docente no Programa de Pós-Graduação em Ciências Sociais da UFSM; Pesquisador do Núcleo de Estudos sobre Emoções e Realidades Digitais (NEERD) da UFSM. Rua Venâncio Aires, 1742 - Centro

Caixa Postal 42

97010-970 Santa Maria, RS, Br

framses@gmail.com

This is an open-access article, which permits unrestricted use, distribution, and reproduction in any medium for non-commercial purposes provided the original authors and sources are credited. 